\title{
Anticorpos revelados pelo teste de inibição do crescimento de leptospiras in vitro (TICL) contra os sorovares Canicola, Icterohaemorrhagiae e Copenhageni em cães adultos revacinados anualmente com vacina comercial contendo bacterinas dos sorovares Canicola, Icterohaemorrhagiae, Grippotyphosa e Pomona ${ }^{1}$
}

\author{
Angela M.A. Rodrigues ${ }^{2}$, Silvio A. Vasconcelos ${ }^{3}$, Amane P. Gonçales ${ }^{4}$, Zenaide M. \\ de Moraes $^{3}$, Gisele O. de Souza ${ }^{3}$ e Mitika K. Hagiwara ${ }^{5 *}$
}

\begin{abstract}
Rodrigues A.M.A., Vasconcelos S.A., Gonçales A.P., Moraes Z.M., Souza G.O. \& Hagiwara M.K. 2013. [Antibody revealed by growth inhibition test the of leptospires in vitro (GIT) against serovars Canicola, Icterohaemorrhagiae and Copenhageni in adult dogs revaccinated annually with commercial vaccine containing serovars Canicola, Icterohaemorrhagiae, Grippotyphosa and Pomona bacterins.] Anticorpos revelados pelo teste de inibição do crescimento de leptospiras in vitro (TICL) contra os sorovares Canicola, Icterohaemorrhagiae e Copenhageni em cães adultos revacinados anualmente com vacina comercial contendo bacterinas dos sorovares Canicola, Icterohaemorrhagiae, Grippotyphosa e Pomona. Pesquisa Veterinária Brasileira 33(5):627-634. Departamento de Clínica Médica, Faculdade de Medicina Veterinária e Zootecnia, Universidade de São Paulo, Av. Prof. Dr. Orlando Marques de Paiva 87, Cidade Universitária, São Paulo, SP 05508-270, Brazil. E-mail: mitika.hagiwara@gmail.com

Currently, the serovar Copenhageni is the representative of serogroup Icterohaemorrhagiae maintained in synanthropic rodents found most frequently in dogs and humans in metropolitan areas of Brazil. Despite some authors have suggested the existence of cross-protection between serovars included in the same serogroup, this condition has not yet been sufficiently clarified for serovars Icterohaemorrhagiae and Copenhageni. In the present work, 2 to 6-year-old dogs, vaccinated at 60, 90 and 120 days of age and thereafter, revaccinated annually with commercial vaccine containing Canicola, Icterohaemorrhagiae, Grippotyphosa and Pomona bacterins were evaluated as to the immune status against leptospirosis before and 30 days after revaccination. Mycroscopic agglutination test (MAT) and in vitro growth inhibition test (GIT) were performed to search for agglutinating anti-Leptospira antibodies and neutralizing anti-Leptospira antibodies, respectively for serovars Canicola and Icterohaemorrhagiae, and additionally, for serovar Copenhageni, not included in the vaccine. The results showed that the immunity conferred by the vaccine to serovar Icterohaemorrhagiae is more lasting than that observed for serovar Canicola, since neutralizing antibody titers $>1.0 \log 10$ were observed before the booster vaccination with no substantial increase after revaccination. As for the serovar Canicola, revaccination resulted in a considerable increase in neutralizing antibody titer when compared to the one observed previously to the revaccination $(p=0.001)$. The analysis of the data obtained by GIT allowed us to conclude that dogs given vaccine containing
\end{abstract}

\footnotetext{
${ }^{1}$ Recebido em 7 de dezembro de 2012.

Aceito para publicação em 28 de janeiro de 2013

${ }^{2}$ M. Cassab Comércio e Indústria Ltda, Av. das Nações Unidas 20882, São Paulo, SP 04795-000, Brasil.

${ }^{3}$ Departamento de Medicina Veterinária Preventiva e Saúde Animal, Faculdade de Medicina Veterinária e Zootecnia (FMVZ), Universidade de São
}

Paulo (USP), Av. Prof. Dr. Orlando Marques de Paiva 87, Cidade Universitária, São Paulo, SP 05508-270.

${ }^{4}$ Laboratório de Bacteriologia, Instituto Butantan, Av. Vital Brasil 1500, São Paulo, SP 05503-900.

${ }^{5}$ Departamento de Clínica Médica, FMVZ-USP, São Paulo, SP. *Autor para correspondência: mitika.hagiwara@gmail.com 
Icterohaemorrhagiae bacterin did not produce neutralizing antibodies against serovar Copenhageni enough to inhibit leptopiral growth at the same level as occurred for the homologous serovar. Despite this, the GIT titer found for serovar Copenhageni before and after revaccination showed that at least, some level of protection could be expected for dogs vaccinated with serovar Icterohaemorrhagiae bacterin, not a complete cross protection.

INDEX TERMS: Dogs, leptospirosis, vaccination, cross-protection between serovars.

RESUMO.- Na atualidade, o sorovar Copenhageni é o representante do sorogrupo Icterohaemorrhagiae, mantido por roedores sinantrópicos, que tem prevalecido nos cães e seres humanos das grandes metrópoles brasileiras. A despeito de alguns autores sugerirem a existência de proteção cruzada entre sorovares incluídos em um mesmo sorogrupo esta condição ainda não foi suficientemente esclarecida para os sorovares Icterohaemorrhagiae e Copenhageni. No presente trabalho cães adultos com dois a seis anos de idade primo-vacinados com três doses intervaladas de 30 dias a partir dos 60 dias de idade e revacinados anualmente com vacina anti-leptospirose polivalente contendo os sorovares Canicola, Icterohaemorrhagiae, Grippotyphosa e Pomona foram revacinados com a mesma vacina e aos 30 dias da revacinação foram submetidos aos testes de soroaglutinação microscópica (SAM) e de inibição do crescimento de leptospiras in vitro (TICL), para avaliação comparativa dos níveis de anticorpos produzidos para os sorovares Canicola, Icterohaemorrhagiae e Copenhageni. Os resultados obtidos indicaram que a imunidade conferida pela vacina para o sorovar Icterohaemorrhagiae é mais duradoura que a observada para o sorovar Canicola, já que títulos de anticorpos neutralizantes $>1,0 \log _{10}$ foram observados antes do reforço vacinal não havendo substancial aumento após a revacinação. Quanto ao sorovar Canicola, a revacinação resultou em considerável aumento do título de anticorpos neutralizantes quando comparado ao momento anterior a revacinação $(p=0,001)$. A análise dos valores encontrados após a revacinação demonstrou claramente que cães revacinados com bacterina produzida com o sorovar Icterohaermorrhagiae não apresentam aumento do título de anticorpos inibidores do crescimento contra o sorovar Copenhageni, em nível suficiente para inibir o crescimento de leptospiras. Apesar disso, os títulos de anticorpos inibidores de crescimento anti-Copenhageni encontrados antes e após a revacinação demonstraram que, pelo menos certo grau de proteção contra a infecção por esse sorovar pode ser esperado para os cães vacinados com bacterinas do sorovar Icterohaemorrhagiae, não sendo, no entanto, uma proteção cruzada completa.

TERMOS DE INDEXAÇÃO: Cães, leptospirose, vacinação, proteção cruzada entre sorovares.

\section{INTRODUÇÃO}

A leptospirose canina foi descrita inicialmente há mais de um século, tendo sido reconhecidas as formas hepatonefrítica, caracterizada por icterícia, hemorragia e insuficiência renal e a nefrítica primordialmente com comprometimento renal agudo e uremia (Greene et al. 2012). Leptospiras patogênicas dos sorogrupos Icterohaemorrhagiae e Canicola foram associadas à maioria dos casos clínicos de leptospirose em cães, embora a infecção por leptospiras de outros sorogrupos também tenha sido demonstrada por técnicas sorológicas (Stokes et al. 2007) ou por isolamento do agente em cães doentes ou aparentemente hígidos (Goldstein et al. 2006). Bacterinas preparadas com culturas de estirpes patogênicas dos sorovares Icterohaemorrhagiae e Canicola passaram a ser empregadas para a prevenção da leptospirose canina e continuam sendo amplamente utilizadas ao redor do mundo (Sonrier et al. 2001, Sykes et al. 2011, Green et al. 2012). 0 amplo uso das vacinas comerciais preparadas com esses sorovares contribuiu, entre outras causas, para a redução da infecção dos cães pelos sorovares Icterohaemorrhagiae e Canicola nos países da Europa (Geisen et al. 2007) e da América do Norte (Goldstein et al. 2006). Outros sorovares patogênicos para os cães como Grippotyphosa, Pomona, ou Bratislava passaram a ter maior importância na epidemiologia da leptospirose naqueles países (Geisen et al. 2007; Stokes et al. 2007,). Entretanto, na maioria das regiões tropicais ainda prevalece a infecção dos cães por leptospiras dos sorogrupos Icterohaemorrhagiae e Canicola (Suepaul et al. 2010a).

No Brasil, o sorovar Copenhageni é, dentre as variantes sorológicas incluídas no sorogrupo Icterohaemorrhagiae, o mais prevalente, tanto nas infecções humanas quanto nas diferentes espécies de animais domésticos ou silvestres. Surtos de leptospirose humana foram associados ao sorovar Copenhageni (Ko et al. 1999, Pereira et al. 2000) e estudos epidemiológicos e clínicos têm demonstrado a maior prevalência sorológica desse sorovar nas infecções humanas (Romero et al. 2003, Romero \& Yasuda 2006). Estirpes de leptospiras isoladas ao longo dos anos de casos de leptospirose humana, reconhecidas inicialmente como Icterohaemorrhagiae, foram caracterizadas molecularmente como sorovar Copenhageni (Romero \& Yasuda 2006). Estirpes de leptospiras do sorovar Copenhageni também foram isoladas de cães (Yasuda et al. 1980, Cordeiro \& Sulzer 1983, Rodrigues et al. 2012), dos animais de produção (Zacarias et al. 2008) e silvestres e sinantrópicos (Correa et al. 2004). A infecção por Copenhageni também tem sido amplamente demonstrada de forma indireta na reação de SAM nos casos clínicos suspeitos de leptospirose canina (Favero et al. 2002, Freire et al. 2007). Os sorovares Icterohaemorrhagiae e Copenhageni pertencem ao mesmo sorogrupo e apresentam similaridade antigênica e molecular (Arimitsu et al. 1980) e a reatividade cruzada entre ambos é evidenciada quando se incluem, na coleção de antígenos da reação SAM, os dois sorovares. Diferenças antigênicas entre os sorovares Icterohaemorrhagiae e Copenhageni foram confirmadas em ensaios que empregam conjuntos de anticorpos monoclonais (Korver et al. 1988, Hookey \& Palmer 1991, Rodrigues et al. 2012).

A imunidade contra a leptospirose é predominantemente humoral e fortemente restrita ao sorovar homólogo (Levett 2001, Koizumi \& Watanabe 2005, Greene et al. 2012), confe- 
rida por antígenos LPS da membrana das leptospiras (Sonrier et al. 2001). A proteção promovida por LPS de leptospiras é completa para os sorovares homólogos e apenas parcial para os sorovares heterólogos (Minke et al. 2009). As bacterinas anti-leptospirose podem eliciar proteção contra o desenvolvimento de doença, mas não necessariamente contra o estabelecimento do estado de portador renal (Klaasen et al. 2003, Minke et al. 2009). Existem evidências de haver certo grau de proteção cruzada entre sorovares distintos incluídos em um mesmo sorogrupo (Sonrier et al. 2001) tais como Icterohaemorrhagiae e Copenhageni (Freudenstein \& Hein 1991) ou Hardjo, Wolffi e Guaricura incluídos no sorogrupo Sejroe (Tabata et al. 2002) eliciada pelos componentes proteicos da membrana externa das leptospiras. Apesar disso, considerando-se a imunidade mais específica desenvolvida, sugere-se que as vacinas anti-leptospirose sejam formuladas com os sorovares predominantes na região e na população ou grupo de animais a ser imunizado (Levett 2001, Suepaul et al. 2010b). A maioria das vacinas anti-leptospirose canina comercializadas no Brasil inclui na sua composição, antígenos oriundos de cultivos inativados do sorovar Icterohaemorrhagiae (Langoni et al. 2002, Mucciolo 2010) embora os diversos estudos epidemiológicos realizados apontem para a maior ocorrência de infecção em cães pelo sorovar Copenhageni (Yasuda et al. 1980, Rodrigues et al. 2012)

0 teste de soroaglutinação microscópica (SAM) amplamente utilizado para o diagnóstico da leptospirose (Levett 2001) revela anticorpos aglutinantes predominantemente do tipo IgM (Hartmann et al. 1984) os quais não neutralizam completamente ou não são capazes de destruir o organismo e portanto, não são indicados para a avaliação da resposta vacinal e proteção dada pelas vacinas (Greene et al. 2012). 0 grau de proteção se correlaciona melhor com anticorpos opsonizantes, capazes de promover a fagocitose das bactérias. (Hartmann et al. 1984, Greene et al. 2012). O método de controle da eficácia de bacterinas anti-leptospirose animal oficialmente adotado é o teste de potência com desafio em hamsters (Tabata et al. 2002, Suepaul et al. 2010b). No entanto, este procedimento tem como limitações o emprego de animais de laboratório e de estirpes de leptospiras patogênicas, com risco da ocorrência de acidentes entre os manipuladores. Uma alternativa proposta (Tripathy et al. 1973) é o teste de inibição do crescimento de leptospiras in vitro que revela a presença de anticorpos neutralizantes da classe IgG e que dispensa o uso de animais de laboratório e de estirpes de leptospiras patogênicas (Tabata et al. 2002, Gonçales 2007, Nardi et al. 2010).

0 objetivo do presente trabalho foi o de empregar o teste de inibição do crescimento de leptospiras in vitro (TICL) para a avaliação dos níveis de anticorpos inibidores do crescimento das leptospiras dos sorovares Canicola, Icterohaemorrhagiae e Copenhageni em cães imunizados com uma vacina anti-leptospirose comercial produzida com bacterinas dos sorovares Canicola, Icterohaemorrhagiae. Grippotyphosa e Pomona.

\section{MATERIAL E MÉTODOS}

\section{Animais e delineamento experimental}

Foram incluídos no estudo 24 cães adultos, utilizados como cães de guarda, das raças Pastor Alemão, Rottweiler e Labrador, sendo dez fêmeas e 14 machos, de dois a seis anos de idade (2 anos, $n=8 ; 3$ anos, $n=1 ; 4$ anos, $n=7 ; 5$ anos, $n=2 ; 6$ anos, $n=6$ ). 0 estudo foi realizado, por ocasião da revacinação anual dos cães, com a anuência do responsável e aprovação do Comitê de Bioética, em consonância com as normas vigentes. Os cães haviam sido vacinados aos dois, três e quatro meses de idade e posteriormente, revacinados anualmente com uma vacina comercial contendo cinco antígenos virais e quatro bacterinas sorovares Canicola, Icterohaemorrhagiae, Grippotyphosa e Pomona de Leptospira. Por ocasião da realização do estudo, a última aplicação da vacina havia sido realizada há doze meses. Todos os cães se encontravam em boas condições de saúde e no exercício de suas atividades rotineiras. Os cães foram então revacinados com a mesma vacina comercial. Foram coletadas amostras de sangue imediatamente antes e trinta dias após à revacinação, para a avaliação do título de anticorpos aglutinantes por meio da reação de soroaglutinação microscópica (SAM) e do título de anticorpos neutralizantes, por meio do teste de inibição de crescimento das leptospiras "in vitro" (TICL).

\section{Teste de soroaglutinação microscópica (SAM)}

0 teste de SAM para a mensuração do título de anticorpos aglutinantes foi realizado de acordo com a técnica descrita por Cole et al. (1973) tendo como antígenos vinte e duas estirpes de leptospira patogênicas e duas de leptospiras saprófitas: Australis, Bratislava, Autumnalis, Butembo, Castellonis, Bataviae, Canicola, Whitcombi, Cynopteri, Grippotyphosa, Javanica, Panama, Pomona, Pyrogenes, Hardjo, Wolffi, Shermani, Tarassovi, Andamana, Icterohaemorrhagiae, Copenhageni, Hebdomadis, Patoc e Sentot. As estirpes de leptospiras empregadas foram cultivadas em meio liquido de EMJH modificado (Alves et al. 1996) com sete a dez dias de cultivo contendo cerca de 100 a 200 leptospiras por campo microscópico, no aumento de 200 vezes. Os soros foram diluídos com PBS na diluição de 1:50 e testados contra toda a coleção de antígenos vivos. A diluição final da mistura soro:antígeno foi de 1:100 e considerado o limiar da reação (cut off). Os soros que apresentaram $50 \%$ de leptospiras aglutinadas por campo microscópico foram titulados com os respectivos antígenos em uma série geométrica de diluições de razão dois. 0 título considerado foi a recíproca da maior diluição que apresentou $50 \%$ de leptospiras aglutinadas por campo microscópico.

\section{Teste de inibição de crescimento de leptospiras in vitro (TICL)}

0 teste de inibição de crescimento de leptospiras in vitro (TICL) foi realizado em conformidade com a técnica descrita por Tripathy et al. (1971), Tabata et al. (2002), Nardi et al. (2010) e Soto et al. (2011). A amostra de soro foi dividida em quatro alíquotas, das quais três foram diluídas em escala geométrica de razão dois $(1: 2,1: 4,1: 8,1 ; 16$ e 1:32) em solução salina tamponada de Sorensen e uma foi mantida sem diluição, servindo como controle da reação. Cada uma das alíquotas foi destinada ao teste de inibição de crescimento dos sorovares Copenhageni, Icterohaemorrhagiae ou Canicola, respectivamente. Foram preparados cinco tubos por diluição, para cada um dos sorovares avaliados. Em cada tubo de cultivo foram adicionados 2,5mL de meio líquido de EMJH modificado (Alves et al. 1996); $200 \mu \mathrm{L}$ da diluição do soro e $100 \mu \mathrm{L}$ de cultura viva de um dos três sorovares investigados com sete a dez dias de cultivo em meio de EMJH modificado. Os tubos foram incubados a $28-30^{\circ} \mathrm{C}$ por dez dias e após esse período, examinados para observação do crescimento de leptospiras. Os tubos em que não foi observada turvação a olho nu e com menos de dez leptospiras por campo (aumento de 120X) em microscopia de campo escuro foram considerados positivos para a inibição do crescimento. A diluição de soro (expressa em $\log _{10}$ ), capaz de inibir o crescimento das leptospiras de um sorovar em $50 \%$ dos tubos de cada diluição do soro foi calculada pelo método de Reed \& Muench (Mancuso 1974). 
Os títulos de anticorpos inibidores do crescimento de leptospiras foram transformados em $\log _{10}$ e os respectivos intervalos de confiança de 95\% (IC95\%) das médias geométricas foram calculados com a fórmula de Pizzi (1950). Títulos $\geq 1,0 \log _{10}$ foram considerados protetores (Gonçales 2007). A existência de possível proteção cruzada entre os sorovares Icterohaemorrhagiae e Copenhageni foi avaliada, superpondo-se os valores nos intervalos de confiança obtidos para ambos os sorovares. 0 método não paramétrico de Kruskal Wallis foi utilizado para a comparação dos títulos obtidos entre os sorovares no TICL em ambos os momentos analisados (antes ou após a revacinação) e o teste de Mann-Whitney para as comparações entre os momentos.

\section{RESULTADOS}

Previamente a revacinação, todos os cães apresentaram resultados negativos no teste de SAM, não apresentando, portanto, títulos de anticorpos aglutinantes antileptospiras iguais ou superiores ao título 100 para nenhuma das leptospiras incluídas na coleção de antígenos. Trinta dias após a vacinação, 11 animais (44\%) apresentaram títulos de anticorpos aglutinantes para os sorovares Canicola, Icterohaemorrhagiae, Copenhageni, Grippotyphosa, Pomona, Butembo, variando de 200 a 800 . Nenhum dos animais apresentou anticorpos aglutinantes contra o sorovar Canicola (Quadro 1).

No teste de inibição de crescimento de leptospiras in vitro, os soros colhidos antes da aplicação do imunógeno

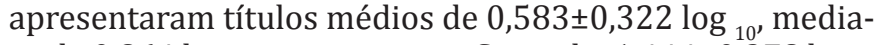
na de $0,864 \log _{10}$ para o sorovar Canicola; 1,444 $\pm 0,278 \log _{10}$ mediana $1,656 \log _{10}$ para o sorovar Icterohaemorrhagiae e $0,725 \pm 0,317 \log _{10}$, mediana 0,668 $\log _{10}$ para o sorovar Copenhageni. Após a revacinação, os títulos obtidos foram de $1,475 \pm 0,270 \log _{10} 1,455 \pm 0,287 \log _{10}$ e $0,510 \pm 0,304 \log _{10}$, respectivamente para os sorovares Canicola, Icterohaemorrhagiae e Copenhageni. (Quadro 2). Na Figura 1 são
Quadro 1. Distribuição dos títulos de anticorpos aglutinantes antileptospiras segundo o sorovar reagente, obtidos por meio da reação de soroaglutinação microscópica (SAM) dos soros colhidos de cães adultos $\mathbf{3 0}$ dias após a re-vacinação com vacina tetravalente (Canicola, Icterohaemorrhagiae, Grippotyphosa e Pomona)

\begin{tabular}{lccccc}
\hline \multicolumn{1}{c}{ Sorovar reagente } & \multicolumn{5}{c}{ Títulos de anticorpos aglutinantes } \\
& \multicolumn{5}{c}{ antileptospiras } \\
\cline { 2 - 6 } & 100 & 200 & 400 & 800 & $\begin{array}{c}\text { Total de reações } \\
\text { positivas }\end{array}$ \\
\hline Canicola & 0 & 0 & 0 & 0 & 0 \\
Icterohaemorrhagiae & 0 & 1 & 0 & 1 & 2 \\
Copenhageni & 0 & 3 & 1 & 1 & 5 \\
Grippotyphosa & 0 & 4 & 3 & 2 & 9 \\
Pomona & 1 & 2 & 1 & 2 & 6 \\
Butembo & 2 & 3 & 2 & 0 & 7 \\
Total de reações positivas & 3 & 13 & 7 & 6 & 29
\end{tabular}

apresentados sob a forma de box plot a mediana, primeiro e terceiro quartis, e o intervalo de confiança dos títulos de anticorpos inibidores de crescimento contra os sorovares

Quadro 2. Médias geométricas e intervalos de confiança de 95\% $\left(\log _{10}\right.$ e antilog $\left.{ }_{10}\right)$ dos títulos de anticorpos inibidores do crescimento de leptospiras observados em cães adultos revacinados contra leptospirose com vacina tetravalente (Canicola, Icterohaemorrhagiae, Grippotyphosa e Pomona) segundo o sorovar de leptospira incluído no teste, antes e trinta dias após a vacinação

\begin{tabular}{cccccc}
\hline \multirow{2}{*}{$\begin{array}{c}\text { Variante } \\
\text { sorológica }\end{array}$} & \multicolumn{2}{c}{ Pré-vacinal } & & \multicolumn{2}{c}{ Pós-vacinal* } \\
\cline { 2 - 3 } \cline { 5 - 6 } & $\log _{10}$ & Antilog $_{10}$ & & $\log _{10}$ & Antilog $_{10}$ \\
\hline Canicola & $0,725 \pm 0,317$ & $5,312 \pm 2,074$ & & $1,475 \pm 0,270$ & $29,863 \pm 1,863$ \\
$\begin{array}{c}\text { Icterohaemor- } \\
\text { rhagiae }\end{array}$ & $1,444 \pm 0,278$ & $27,793 \pm 1,898$ & & $1,455 \pm 0,287$ & $28,485 \pm 1,936$ \\
Copenhageni & $0,583 \pm 0,322$ & $3,829 \pm 2,097$ & & $0,510 \pm 0,304$ & $3,232 \pm 2,014$
\end{tabular}

* Colheita de sangue efetuada aos 30 dias da aplicação da vacina anti-leptospira.

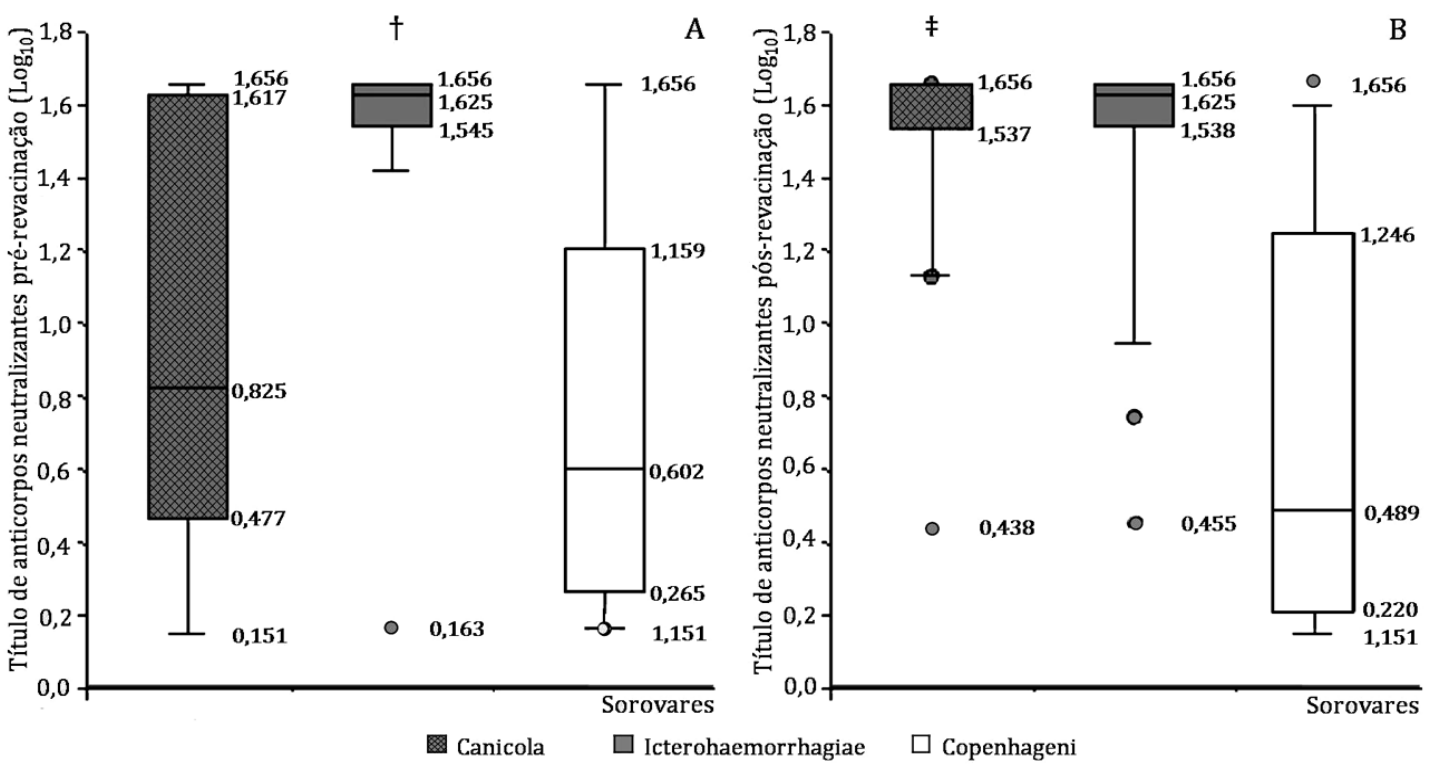

Fig.1. Box plot representativo dos títulos de anticorpos inibidores do crescimento determinados pelo teste de inibição de crescimento (expressos em logarítimo de base 10) dos sorovares Canicola, Icterohaemorrhagiae e Copenhageni em cães adultos revacinados contra a leptospirose com vacina tetravalente (Canicola, Icterohaemorrhagiae, Grippotyphosa e Pomona) antes (A) e após (B) a revacinação. † Diferença significativa entre os diferentes sorovares no mesmo momento $(\mathrm{p}<0,001)$; Diferença entre os momentos pré e pós vacinal para o sorovar Canicola $(\mathrm{p}=0,001)$. 

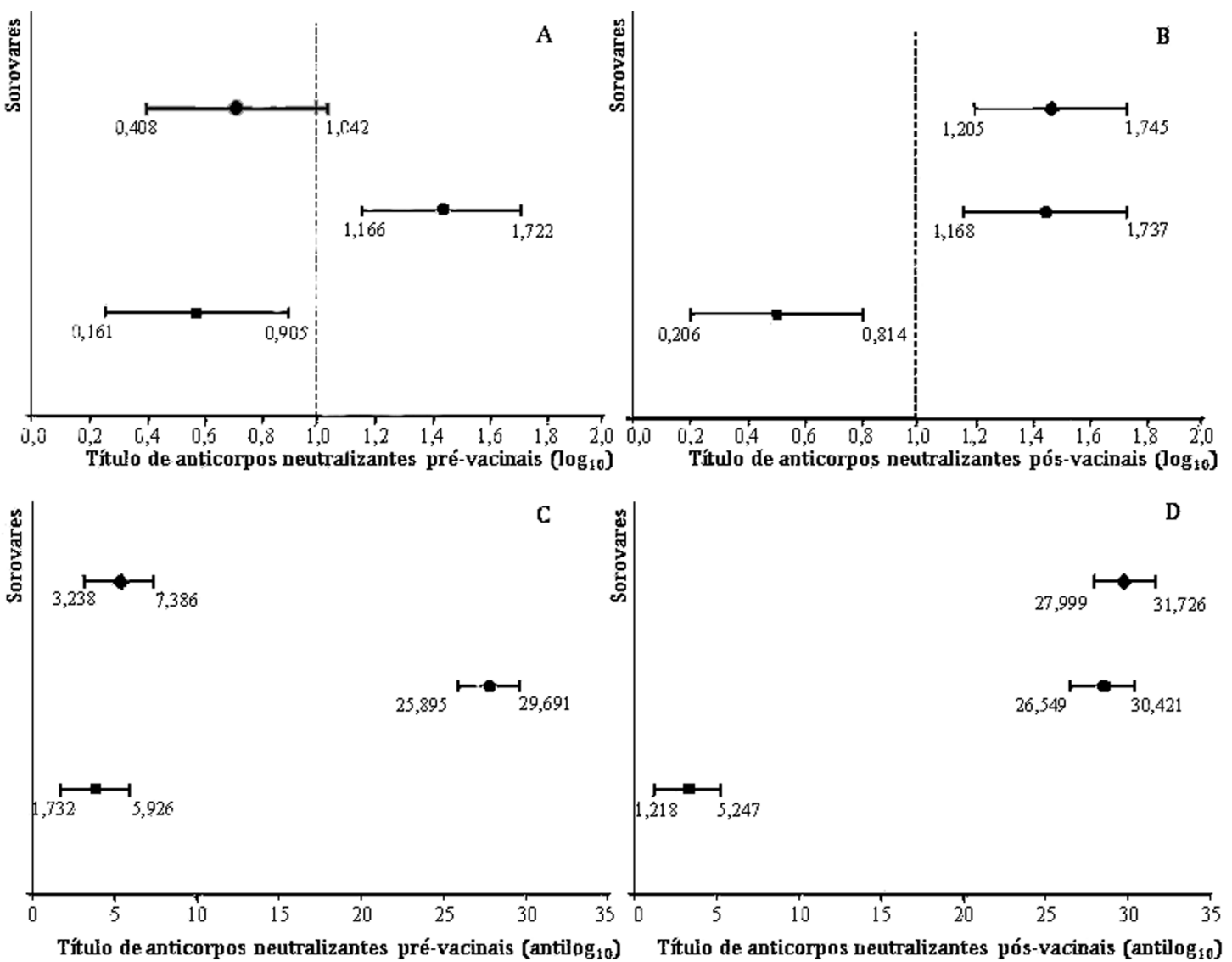

Fig.2. Médias geométricas e intervalos de confiança (95\%) dos níveis de anticorpos inibidores do crescimento contra os sorovares Canicola $(\bullet)$, Icterohaemorrhagiae $(\bullet)$ e Copenhageni $(\bullet)$, expressos em valores logarítimos de base dez $(\mathbf{A}, \mathbf{B})$ e antilogarítimos de base dez (C,D), dos soros dos cães adultos revacinados contra a leptospirose com vacina tetravalente (Canicola, Icterohaemorrhagiae, Grippotyphosa e Pomona), antes $(\mathbf{A}, \mathbf{C})$ e trinta dias após a revacinação (B,D).

Canicola, Icterohaemorrhagiae e Copenhageni, respectivamente, antes e após a vacinação. Houve uma elevação significativa nos títulos de anticorpos produzidos contra o sorovar Canicola quando comparada ao momento pré-vacinal (mediana $=1,656 \log _{10} ; \mathrm{p}=0,001$ ). Já os títulos obtidos contra os sorovares Icterohaemorrhagiae (mediana $=1,625$ $\log _{10}$ ) e Copenhageni (mediana $=0,677 \log _{10}$ ) não foram distintos dos respectivos valores observados no momento pré-vacinal $(\mathrm{p}>0,5)$. Também após a vacinação, os títulos de anticorpos inibidores do crescimento contra o sorovar Copenhageni foram significativamente distintos e inferiores $(p<0,001)$ aos observados contra os sorovares Icterohaemorrhagiae e Canicola, presentes na vacina.

A Figura 2 apresenta as médias geométricas e os intervalos de confiança (95\%) dos títulos de anticorpos inibidores do crescimento de leptospiras, expressos em valores logarítmicos e antilogarítmicos de base 10, contra os sorovares Canicola, Icterohaemorrhagiae e Copenhageni nos soros colhidos antes e após a revacinação.

\section{DISCUSSÃO}

A ausência de anticorpos aglutinantes detectáveis (título positivo $\geq 100$ ) em cães no momento anterior ao reforço vacinal anual encontra respaldo na literatura (Castro et al. 2011) considerando-se que os títulos de aglutininas séricas geralmente diminuem rapidamente após o uso de bacterinas (Greene et al. 2012). A reação de SAM revela a presença principalmente de anticorpos aglutinantes, do tipo IgM de curta duração. A vacinação primária não estimula produção substancial de IgG, porém após os reforços vacinais, ocorre aumento rápido do título de anticorpos, na dependência das características do antígeno utilizado e posteriormente, queda do título a níveis mínimos em 4 a 6 meses (Hartmann et al. 1984). O sorovar Canicola não estimula a produção de anticorpos aglutinantes em títulos detectáveis na maioria dos cães nas vacinações, primárias ou secundárias de reforço, refletindo as variações biológicas das leptospiras, o poder imunogênico de uma bacterina (Suepaul et al. 2010b) e a adaptação ao hospedeiro (Hartmann et al. 1984). Justifica-se assim, a ausência de título de anticorpos aglutinantes anti-sorovar Canicola antes e após a aplicação das vacinas observadas neste estudo, como foi também demonstrado por Minke et al. (2009), Mucciolo (2010) e Castro et al. (2011).

Trinta dias após a vacinação, 44\% (11/24) dos animais apresentaram aglutininas contra os sorovares: Icterohaemorrhagiae, Gryppotyphosa, Pomona, Butembo e Copenhageni. Os dois últimos sorovares não estavam incluídos na composição da vacina empregada. A ocorrência de reações cruzadas entre sorovares de um mesmo sorogrupo 
ou de sorogrupos distintos é comum, incluindo as reações "paradoxais", nas quais a resposta imune inicial pode ser mais intensa para sorovares ou sorogrupos heterólogos (Gitton et al. 1994, Levett 2001, Barr et al. 2005, Stokes et al. 2007, Castro et al. 2011). Algumas proteínas antigênicas se conservam entre os diferentes sorovares, resultando em reações cruzadas (Gamberini et al. 2005). Fato interessante é que 56\% (13/24) dos cães não apresentaram qualquer taxa de anticorpos aglutinantes, no ponto de corte adotado, confirmando o fato já conhecido de que os títulos de anticorpos aglutinantes desenvolvidos após a vacinação são de baixa intensidade (André-Fontaine et al. 2003, Koizumi \& Watanabe 2005) e de curta duração (Barr et al. 2005), sendo eventualmente inexistentes para um ou mais sorovares incluídos nas vacinas (Klaasen et al. 2003, Castro et al. 2011). A ausência de títulos de anticorpos aglutinantes como ocorreu na totalidade dos cães vacinados em relação ao sorovar Canicola ou parcialmente em relação ao sorovar Icterohaemorrhagiae não significa ausência de resposta protetora eliciada pela vacina. De acordo com André-Fontaine et al. (2003), Klaasen et al. (2003) e Mucciolo (2010), não há correlação entre título de anticorpos aglutinantes após a vacinação e proteção contra os desafios e apenas os testes mais específicos como o teste de desafio em hamsters podem indicar a eficiência das bacterinas na proteção contra as infecções experimentais ou naturais.

Diferentemente do teste de SAM, o teste de inibição de crescimento in vitro (TICL) revelou a presença de anticorpos neutralizantes para os sorovares Canicola e Icterohaemorrhagiae, tanto no momento pré-vacinal quanto trinta dias após a vacinação. Da mesma forma, os anticorpos presentes nos cães também foram capazes de inibir parcialmente o crescimento de leptospiras do sorovar Copenhageni, não incluído entre os antígenos vacinais, em ambos os momentos estudados. As vacinas contra leptospirose conferem uma imunidade de duração variável de três meses (Hartmann et al. 1984) a treze meses (Klaasen et al. 2003) na dependência da concentração do antígeno vacinal, do número de doses aplicadas e da estirpe do sorvar empregado na produção da bacterina Em geral, considera-se a duração de imunidade de doze meses (Greene et al. 2012).

Embora no início do experimento os cães não apresentassem títulos de anticorpos aglutinantes para a coleção de 24 estirpes de leptospiras empregadas, foi possível observar títulos de anticorpos neutralizantes para os três sorovares investigados. A divergência entre a reação de SAM e o TICL in vitro foi relatada em búfalos (Nardi et al. 2010), suínos (Soto et al. 2011) e hamsters (Tabata et al. 2002). Considerando-se o título $1,0 \log _{10}$ como indicativo de proteção (Gonçales 2007), no momento pré-vacinal os cães encontravam-se protegidos apenas contra a infecção pelo sorovar Icterohaemorrhagiae e não estariam protegidos contra a infecção por Canicola ou pelo sorovar Copenhageni. 0 teste de inibição de crescimento não foi aplicado para os sorovares Grippotyphosa e Pomona. Após a revacinação, não houve incremento dos títulos de anticorpos inibidores do crescimento de leptospiras para os sorovares Icterohaemorrhagiae e Copenhageni. Entretanto, em relação ao sorovar Canicola houve uma significativa elevação dos títulos ( $\mathrm{p}<0,001)$, ultrapassando os níveis considerados protetores $(>1,0 \log 10)$, de acordo com Gonçales (2007), indicando que a vacina empregada estimulou o desenvolvimento da imunidade humoral contra esse sorovar. Também nesse momento não foram observados resultados positivos na reação de SAM para esse sorovar, comprovando-se novamente a inexistência da correlação entre título de anticorpos aglutinantes e anticorpos neutralizantes e consequentemente, proteção contra o desafio (Greene et al. 2012). Em relação ao sorovar Icterohaemorrhagiae, o reforço antigênico não resultou em elevação considerável nos títulos de anticorpos neutralizantes, mantendo-se nos patamares observados antes do reforço vacinal, quando estavam presentes em níveis protetores $\left(>1,0 \log _{10}\right)$. Isto pode ser explicado pela baixa imunogenicidade da bacterina utilizada ou pela imunidade humoral em nível suficiente para inibir resposta imunológica adicional. A despeito dos sorovares Icterobaemorrhagiae e Copenhageni estarem incluídos em um mesmo sorogrupo, a estirpe do sorovar Icterohaemorrhagiae utilizada na fabricação da bacterina também não foi capaz de promover a elevação dos níveis de anticorpos protetores contra o sorovar Copenhageni. Os títulos inicialmente baixos, não alcançaram níveis protetores após o reforço vacinal. A ausência de superposição dos valores apresentados nos intervalos de confiança (95\%) dos títulos de anticorpos inibidores do crescimento obtidos contra os sorovares Copenhageni e Icterohaemorrhagiae (Fig.2) corrobora o baixo nível de proteção cruzada entre ambos o que é confirmado pela expressiva distância entre os valores de $\mathrm{DL}_{50}$ observados e pelos títulos obtidos na TICL com o sorovar Copenhageni, de 0,905 e 0,814 respectivamente, nos momentos pré e pós-vacinais. Portanto, pelos resultados obtidos, pode-se concluir que a vacinação com vacinas contendo o sorovar Icterohaemorrhagiae não promoveu proteção completa contra o sorovar Copenhageni, indicando realmente a necessidade da inclusão dos sorovares predominantes na região, como propõem Suepaul et al. (2010a), no caso brasileiro, do sorovar Copenhageni (Yasuda et al. 1980, Rodrigues et al. 2012). Em ensaio realizado em hamsters vacinados com bacterina comercial contendo o sorovar Icterohaemorrhagiae. Mucciolo (2010) constatou a existência de proteção contra desafio efetuado com a estirpe (L1-130) do sorovar Copenhageni, isolada no Brasil. Por outro lado, Suepaul et al. (2010b) concluíram em Trinidad-Tobago que as vacinas comerciais produzidas com o sorovar Icterohaemorhhagiae não foram capazes de proteger hamsters desafiados com estirpes de leptospiras autóctones do sorovar Copenhageni. Ambos os estudos foram realizados em hamsters e as divergências observadas podem estar relacionadas às características das vacinas utilizadas e a virulência da leptospira patogênica empregada no desafio. Os resultados obtidos em cães no presente estudo confirmaram que a imunidade conferida pelo sorovar Icterohaemorrhagiae foi basicamente sorovar específica; apesar de os sorovares Icterohaemorrhagiae e Copenhageni compartilharem epitopos de sorogrupo (Gamberini et al. 2005), há um elevado grau de diferença nos lipopolissacarídeos do envelope externo destes sorovares que lhes conferem a especificidade exclusiva (Arimitsu et al. 1980). 
Estas diferenças foram confirmadas com sucesso com o emprego de conjuntos de anticorpos monoclonais F70C241 e F70C14-1 (Korver et al. 1988, Hookey \& Palmer 1991, Rodrigues et al. 2012).

A avaliação da eficácia das vacinas e a duração da imunidade pós-vacinal em cães ainda se constitui em um grande desafio, já que os testes de proteção dada pelas vacinas são realizados em hamster (Muciollo 2010, Suepaul et al. 2010b), havendo sérias restrições, principalmente de cunho econômico e ético, da realização dos ensaios na própria espécie animal. Os testes para a comprovação da eficiência das vacinas são realizados em cães (Barr et al. 2005, Minke et al. 2009), porém esses testes não são utilizados para a avaliação da duração da imunidade. Devido às restrições apresentadas pelos testes in vivo e diante da necessidade de avaliação da duração da imunidade com a finalidade de se determinar o adequado intervalo vacinal para os diversos antígenos vacinais dos cães, recomenda-se atualmente a mensuração dos níveis de anticorpos protetores através de técnicas sorológicas (Schultz 2006). Em se tratando da leptospirose, o TICL in vitro poderá se constituir em um dos procedimentos indicados para essa finalidade.

Agradecimentos.- À FAPESP (Proc. 05/57532-8) Bolsa de Mestrado (AMAR) e ao CNPq (Proc. 307312/2006-2) Bolsa de Produtividade em Pesquisa (MKH).

\section{REFERÊNCIAS}

Alves C.J., Vasconcelos S.A., Camargo C.R.A. \& Moraes Z.M. 1996. Influência de fatores ambientais sobre a proporção de caprinos soro-reatores para a leptospirose em cinco centros de criação do Estado da Paraíba, Brasil. Arqs Inst. Biológico, São Paulo, 63(2):11-18.

André-Fontaine G., Branger C., Gray A.W. \& Klaasen H.L.B.M. 2003. Comparison of the efficacy of three commercial bacterins in preventing canine leptospirosis. Vet. Rec. 153(6):165-169.

Arimitsu Y., Mori M. \& Akama K. 1980. Cross antigenicities of Leptospira interrogans serovar Copenhageni Shibaura strain for preparing biological products in Japan. Jap. J. Med. Sci. Biol. 33:223-229.

Barr S.C., McDonough P.L., Scipioni-Ball R.L. \& Starr J.K. 2005. Serologic responses of dogs given a commercial vaccine against Leptospira interrogans serovar pomona and Leptospira kirschneri serovar grippotyphosa. Am. J. Vet. Res. 66(10):1780-1784.

Castro J.R., Souza M.A., Salaberry S.R.S. \& Lima-Ribeiro C.G.A.M.C. 2011. Cinética da resposta imune humoral de cães jovens imunizados. Pesq. Vet. Bras. 31(11):1000-1005.

Cole JR., Sulzer C.R. \& Pursell A.R. 1973. Improved microtechnique for the leptospiral microscopic agglutination test. Appl. Microbiol. 25(6):976980.

Cordeiro F. \& Sulzer C.R. 1983. Leptospira interrogans, serovar Copenhageni, isolated from a dog in Belo Horizonte, Brazil. Revta Microbiol. 14(1):38-41.

Correa S.H.R., Vasconcellos S.A., Morais Z., Teixeira A.A., Dias R.A., Guimarães M.A.B.V., Ferreira F. \& Ferreira Neto J.S. 2004. Epidemiologia da leptospirose em animais silvestres na Fundação Parque Zoológico de São Paulo. Braz. J. Vet. Res. Anim. Sci. 41:189-193.

Favero A.C.M., Pinheiro S.R., Vasconcellos S.A., Moraes Z.M., Ferreira F. \& Neto J.S.F. 2002. Sorovares de leptospira predominantes em exames sorológicos de bubalinos, ovinos, caprinos, equinos, suínos e cães de diversos estados brasileiros. Ciência Rural 32(4):613-619.

Freire I.M.A., Varges A.R.G., Gomes Y.N.P., Pombo C.R. \& Lilenbaum W. 2007. Distribuição dos serovares de leptospira em caninos clinicamente suspeitos no Rio de Janeiro. Revta Bras. Ciênc. Vet. 14(2):83-85.

Freudenstein H. \& Hein B. 1991. Potency of leptospiral vaccines and pro- tection against chronic infection in golden hamsters. Comp. Immunol. Microbiol. Infect. Dis. 14(3):229-234.

Gamberini M., Gomez R.M. \& Atzingen M.V. 2005. Whole-genome analysis of Leptospira interrogans to identify potential vaccine candidates against leptospirosis. FEMS Microbiol. Lett. 244:305-313.

Geisen V., Stengel C., Brem C., Müller W., Greene C. \& Hartmann K. 2007. Canine leptospirosis infections-Clinical signs and outcome with different suspected Leptospira serogroups (42 cases). J. Small Anim. Pract. 48:324-328.

Goldstein R.E., Lin R.C., Langston C.E., Scrivani P.V., Herb H.N. \& Barr S.C. 2006. Influence of Infecting Serogroup on clinical features of leptospirosis in dogs. J. Vet. Intern. Med. 20:489-494.

Gonçales A.P. 2007. Avaliação de vacinas antileptospirose. Relação entre o teste de inibição de crescimento de leptospiras in vitro e o teste de desafio em hamsters. Dissertação de Mestrado em Epidemiologia Experimental Aplicada a Zoonoses, Faculdade de Medicina Veterinária e Zootecnia USP, SP. 96p.

Gitton X., Daubié M.B., André F., Ganière J.P. \& André-Fontaine G. 1994. Recognition of Leptospira interrogans antigens by vaccinated or infected dogs. Vet. Microbiol. 41(1/4):87-97.

Greene C.E., Sykes J.E., Moore G.E., Goldstein R.E. \& Schultz R.D. 2012. Leptospirosis, p.431-447. In: Green C.E. (Ed.), Infectious Disease of the Dog and the Cat. $4^{\text {th }}$ ed. Elsevier Saunders, St Louis.

Hartmann E.G., Van Houten M., Frik J.F. \& Van der Donk J. 1984. Humoral immune response of dogs after vaccination against leptospirosis measured by an IgM- and IgG-specific ELISA. Vet. Immunol. Immunopathol. $7: 245-254$.

Hookey J.V. \& Palmer M.F.A. 1991. A comparative investigation and identification of Leptospira interrogans serogroup icterohaemorrhagiae strains by monoclonal antibody and DNA fingerprint analyses. Zentralbl. Bakteriol. 275:185-189.

Klaasen H.L.B.M., Molkenboer M.J.C.H., Vrijenhoek M.O. \& Kaashoek M.J. 2003. Duration of immunity in dogs vaccinated against leptospirosis with a bivalent inactivated vaccine. Vet. Microbiol. 95:121-132.

Ko A.I., Reis M.G., Ribeiro Dourado C.M., Johnson Jr W.D. \& Riley L.W. 1999. Urban epidemic of severe leptospirosis in Brazil. Lancet 354(9181):820825.

Koizumi N. \& Watanabe H. 2005. Leptospirosis vaccines: Past, present, and future. J. Postgrad. Med. 51(3):210-214.

Korver H., Holk A.H.J., Vingerhoed J., Van Leeuwen J. \& Terpstra W.J. 1988. Classification of serovars of the Icterohaemorrhagiae serogroup by monoclonal antibodies. Isr. J. Vet. Med. 44:15-18.

Langoni H., Pimentel H., Silva A.V., Lucheis S. \& Denardi M. 2002. Avaliação da dinâmica de antiorpos pós-vacinais contra Leptospira spp, em cães vacinados, pela prova de soroaglutinação micorscópica. Ars Vet. 18:54-61.

Levett P.N. 2001. Leptospirosis. Clin. Microbiol. Revs 14:296-314.

Mancuso P.C. 1974. Titulagens: Kärber ou Reed-Muench? Bolm Inst. Pesq. Vet. Desidério Finamor 2:59-71.

Minke J.M., Bey R., Tronel J.P., Latour S., Colombet G., Yvorel J., Cariou C., Guiot A.L., Cozette V. \& Guigal P.M. 2009. Onset and duration of protective immunity against clinical disease and renal carriage in dogs provided by a bi-valent inactivated leptospirosis vaccine. Vet. Microbiol. 137:137-145.

Mucciolo G.B. 2010. Poder imunogênico de bacterina experimental anti-leptospirose canina: ensaio em hamsters desafiados com estirpes de leptospiras dos sorovares Copenhageni e Canicola isolados no Brasil. Dissertação de Mestrado em Epidemiologia Experimental Aplicada a Zoonoses, Faculdade de Medicina Veterinária e Zootecnia, Universidade de São Paulo, SP. 43p.

Nardi Júnior G., Genovez M.E., Ribeiro M.G., Castro V. \& Jorge A.M. 2010. An in vitro growyh inhibition test for measuring the potency of Leptospira spp. Sejroe group vaccine in buffaloes. Biologicals 38:474-478.

Pereira M.M., Matsuo M.G., Bauab A.R., Vasconcelos S.A., Moraes Z.M., Baranton G. \& Saint Girons I. 2000. A clonal subpopulation of Leptospira interrogans sensu stricto is the major cause of leptospirosis outbreaks in Brazil. J. Clin. Microbiol. 38(1):450-452. 
Pizzi M. 1950. Sampling variation of the fifty percent end-point, determined by the Reed-Muench (Behrens) method. Human Biology 22:151190.

Rodrigues A.M.A., Hagiwara M.K., Moraes Z.M., Souza G.O., Gonçalves A.P. \& Vasconcelos S.A. 2012. Isolation and characterization of Leptospira interrogans serovar Copenhageni and serovar Canicola from dogs with leptospirosis. J. Vet. Intern. Med. 26:791-791.

Romero E.C., Bernardo C.C. \& Yasuda P.H. 2003. Human leptospirosis: a twenty- nine-year serological study in Sao Paulo, Brazil. Revta Inst. Med. Trop., São Paulo, 45(5):245-248.

Romero E.C. \& Yasuda P.H. 2006. Molecular characterization of Leptospira sp. strains isolated from human subjects in Sao Paulo, Brazil using a polymerase chain reaction-based assay: a public health tool. Mem. Inst. Oswaldo Cruz 101(4):373-378.

Schultz R.D. 2006. Duration of immunity for canine and feline vaccines: a review. Vet. Microbiol. 117:75-79.

Sonrier C., Branger C., Michel V., Ruvoën-Clouet N., Ganiere J.P. \& AndréFontaine G. 2001. Evidence of cross-protection within Leptospira interrogans in an experimental model. Vaccine 19:86-94.

Soto F.R.M., Delbem A.C.B., Pinheiro S.R., Morais Z.M., Gonçales A.P., Azevedo S.S., Bernardi F., Almeida I.C. \& Vasconcellos S.A. 2011. Comparison of agglutinating and growth inhibition antibodies level in sows immunized with two experimental inactivaed monovalent vaccines of canicola serovar: whole culture with aluminnum hydroxide and lipoplysaccharide subunit with lipid A. Arqs Inst. Biológico, São Paulo, 78(2):199-205.

Stokes J.E., Kaneene J.B., Schall D., Kruger J.M., Miller R., Kaiser L. \& Bolin C.A. 2007. Prevalence of serum antibodies against six Leptospira serovars in healthy dogs. J. Am. Vet. Med. Assoc. 230(11):1657-1664.
Suepaul S.M., Carrington C.V.F., Campbell M., Borde G. \& Adesiyun A.A. 2010a. Serovars of Leptospira isolated from dogs and rodents. Epidemiol. Infect. 138:1059-1070.

Suepaul S.M., Campbell M., Borde G. \& Adesiyun A. 2010b. Study on the efficacy of Leptospira vaccines developed from serovars isolated from Trinidad and comparison with commercial vaccines using a hamster model. Vaccine 28:5421-5426.

Sykes J.E., Hartmann K., Lunn K.F., Moore G.E., Stoddard R.A. \& Goldstein R.E. 2011. 2010 ACVIM small animal consensus statement on leptospirosis: diagnosis, epidemiology, treatment, and prevention. J. Vet. Intern. Med. 25:1-13.

Tabata R., Scavini Neto H., Zuanaze M.A.F., Oliveira E.M.D., Dias R.A., Morais Z.M., Ito F.H. \& Vasconcellos S.A. 2002. Cross neutralizing antibodies in hamsters vaccinated with leptospiral bacterins produced with three serovars of serogroup Sejroe. Braz. J. Microbiol. 33:265-268.

Tripathy D.N., Hansosn L.E. \& Krumrey W. 1971. An in vitro growth inhibition test for leptospiral neutralization. Annu. Meet. U.S. Anim. Health Assoc. 75:138-143.

Tripathy D.N., Hanson L.E. \& Mansfield M.E. 1973. Growth inhibition test for measurement of immune response of animals vaccinated with leptospiral bacterins. Proc. Annu. Meet. U.S. Anim. Health Assoc., St Louis, 77:113-118

Yasuda P.H., Santa Rosa C.A., Myers D.M. \& Yanaguita R.M. 1980. The isolation of leptospires from stray dogs in the city of Sao Paulo, Brazil. Int. J. Zoonoses 7(2):131-134.

Zacarias F.G.S., Vasconcellos S.A., Anzai E.K., Girardi N., Freitas J.C. \& Harstkeel R. 2008. Isolation of Leptospira serovars Canicola and Copenhageni from cattle urine in the State of Parana, Brazil. Braz. J. Microbiol. 39:744748. 